Braz J Med Biol Res, September 2011, Volume 44(9) 939-946

doi: 10.1590/S0100-879X2011007500098

Toxic effects of mercury, lead and gadolinium on vascular reactivity

D.V. Vassallo, M.R. Simões, L.B. Furieri, M. Fioresi, J. Fiorim, E.A.S. Almeida, J.K. Angeli, G.A. Wiggers, F.M. Peçanha and M. Salaices

The Brazilian Journal of Medical and Biological Research is partially financed by

\section{圆CNPq}

da Ciência e Tecnologia

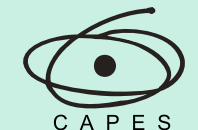

C A P E S
Ministério

da Educação

Institutional S ponsors
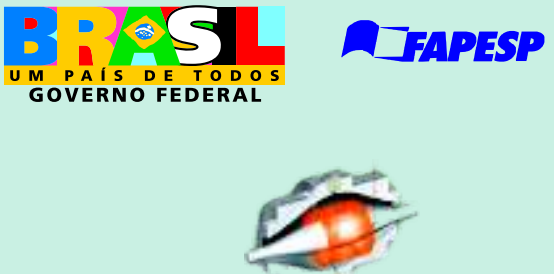

Explore High - Performance MS Protomics

$\underset{\text { analitica }}{\text { analiticaweb.com.br }}$ Thermo 


\title{
Toxic effects of mercury, lead and gadolinium on vascular reactivity
}

\author{
D.V. Vassallo ${ }^{1,2}$, M.R. Simões ${ }^{1}$, L.B. Furieri ${ }^{1,3}$, M. Fioresi ${ }^{1}$, J. Fiorim¹ ${ }^{1}$, E.A.S. Almeida1,2, \\ J.K. Angeli ${ }^{1}$, G.A. Wiggers ${ }^{4}$, F.M. Peçanha ${ }^{4}$ and M. Salaices ${ }^{3}$ \\ ${ }_{1}^{1}$ Programa de Pós-Graduação em Ciências Fisiológicas, Universidade Federal do Espírito Santo, Vitória, ES, Brasil \\ 2Escola Superior de Ciências da Santa Casa de Misericórdia de Vitória, EMESCAM, Vitória, ES, Brasil \\ ${ }^{3}$ Departamento de Farmacología, Universidad Autónoma de Madrid, Madrid, Espanha \\ ${ }^{4}$ Curso de Fisioterapia, Universidade Federal do Pampa, Uruguaiana, RS, Brasil
}

\begin{abstract}
Heavy metals have been used in a wide variety of human activities that have significantly increased both professional and environmental exposure. Unfortunately, disasters have highlighted the toxic effects of metals on different organs and systems. Over the last 50 years, the adverse effects of chronic lead, mercury and gadolinium exposure have been underscored. Mercury and lead induce hypertension in humans and animals, affecting endothelial function in addition to their other effects. Increased cardiovascular risk after exposure to metals has been reported, but the underlying mechanisms, mainly for short periods of time and at low concentrations, have not been well explored. The presence of other metals such as gadolinium has raised concerns about contrast-induced nephropathy and, interestingly, despite this negative action, gadolinium has not been defined as a toxic agent. The main actions of these metals, demonstrated in animal and human studies, are an increase of free radical production and oxidative stress and stimulation of angiotensin l-converting enzyme activity, among others. Increased vascular reactivity, highlighted in the present review, resulting from these actions might be an important mechanism underlying increased cardiovascular risk. Finally, the results described in this review suggest that mercury, lead and gadolinium, even at low doses or concentrations, affect vascular reactivity. Acting via the endothelium, by continuous exposure followed by their absorption, they can increase the production of free radicals and of angiotensin II, representing a hazard for cardiovascular function. In addition, the actual reference values, considered to pose no risk, need to be reduced.
\end{abstract}

Key words: Heavy metal toxicity; Vascular reactivity; Mercury; Lead; Gadolinium

\section{Historical background}

The use of heavy metals is intimately connected to human history. Men discovered metals as important materials for making tools and implements as early as during prehistorical times. However, recorded information about metals does not simply describe their benefits. The contacts of human beings with metal compounds that have no physiological activity, even at low concentrations, are correlated to high levels of toxicity (1). Nowadays several industrial activities and agriculture generate a wide variety of chemical species containing lead, mercury and cadmium, which are in general associated with environmental pollution because of their toxicity and bioaccumulation (1). Metals are also used as ingredients in several compounds for treatments, conservation of vaccines (2) or contrast medium, as is the case for gadolinium (3).

These metals usually induce free radical production and mainly interact with sulfhydryl groups in proteins, altering their activities. The biochemical basis for these effects is often attributed to the inhibition of several ATPases, including $\mathrm{Na}$,K-ATPase (NKA) and Ca-ATPase (4-8), angiotensin Iconverting enzyme (ACE), and to the production of oxidative damage (free radicals by activation of NADPH oxidase).

Correspondence: D.V. Vassallo, Departamento de Ciências Fisiológicas, Universidade Federal do Espírito Santo, Av. Marechal Campos, 1468, 29040-091 Vitória, ES, Brasil. Fax: +55-27-2122-7330. E-mail: daltonv2@terra.com.br

All authors of this review contributed significantly by performing the experiments reported here. Professor Mercedes Salaices was the international adviser of several students of the group during their Doctoral Sandwich Program at Universidad Autónoma de Madrid, Spain.

Presented at the XV Simpósio Brasileiro de Fisiologia Cardiovascular, São Paulo, SP, Brazil, February 2-5, 2011.

Received April 9, 2011. Accepted July 28, 2011. Available online August 12, 2011. Published September $16,2011$. 
Damage resulting from acute or chronic exposure to toxic metals has been mainly described for the nervous system and kidneys (4,8-10). However, increasing knowledge about vascular function including the endothelial-derived mechanisms that regulate vascular tone and the role of enzymes, such as NKA and ACE, and free radicals, has mainly been obtained about metals with vascular function that promote endothelial dysfunction, hypertension and vascular diseases. Recently, the fact that the endothelium is affected by low doses or concentrations of heavy metals has highlighted the importance and the need of improved knowledge of the mechanisms by which these metals promote the development of cardiovascular diseases.

In this review, we will focus on the vascular actions of mercury, lead and gadolinium, heavy metals that we have been studying in our laboratory.

\section{Mercury}

Mercury is worthy of note in this context because of its high toxicity and great mobility in ecosystems. Mercury is known to exert its effects by combining with $\mathrm{SH}$ groups $(4,11)$, which are essential for the normal function of several proteins that constitute enzymes, ion channels or receptors $(11,12)$. These effects include inhibition of ATP hydrolysis and NKA and $\mathrm{Ca}^{2+}$-ATPase activity $(5,7)$.

The US Environmental Protection Agency recommends the reference blood concentration of mercury to be below that considered without adverse effects, which is $5.8 \mathrm{ng} / \mathrm{mL}$ (13). However, in unexposed populations taken as controls, blood mercury concentration was reported to be $2.73 \mathrm{ng} /$ $\mathrm{mL}$ in New York City adults and $1 \mathrm{ng} / \mathrm{mL}$ in China $(14,15)$. For many years mercury was used in diuretics or as an ingredient of antiseptics (4). However, after mercurials were replaced with more specific treatments, signs of mercury intoxication have become rare (10). However, in the past decade, mercury intoxication and poisoning attained high levels $(9,16,17)$ as a result of environmental pollution. The Minamata Bay episode resulting from industrial plastic disposal, the ingestion of contaminated wheat seeds in Guatemala, Iraq and Pakistan, and contamination from metallic mercury used in gold mining in Brazil are examples of this problem $(1,17)$. Human toxicological data about methylmercury poisoning show that symptoms of toxic effects appear at a concentration of mercury in blood of 0.1 $\mu \mathrm{g} / \mathrm{mL}$ and death occurs at concentrations above $3 \mu \mathrm{g} / \mathrm{mL}$ (9). It has also been reported that professional exposure to mercury vapor and the release of mercury from or during the removal of amalgam dental fillings increases the blood and plasma concentration of the metal (18-20). After exposure to mercury vapor, blood concentrations attain $18 \mathrm{nM}$ (20) and, after exposure to dental amalgam fillings and their removal, plasma concentration attains $5 \mathrm{nM}$ (19). Another important mechanism of exposure is fish consumption. Mercury attains $5.65 \mathrm{ng} / \mathrm{mL}$ among regular fish consumers $(13,14)$ and levels of 7 to $10 \mathrm{ng} / \mathrm{mL}$ among exposed workers $(10,15)$.

Recently, more attention has been paid to the toxic effects of mercury on the cardiovascular system and their association with hypertension, carotid atherosclerosis, myocardial infarction, and coronary heart disease (21-23). In the cardiovascular system, acute mercury exposure promotes reduction of myocardial force development (24) and inhibition of myosin ATPase activity (24). Chronic exposure to this metal increases vascular resistance $(25,26)$ and induces hypertension (21).

Functional integrity of the endothelium is crucial for the maintenance of blood flow and antithrombotic capacity because the endothelium releases humoral factors that control relaxation and contraction, thrombogenesis and fibrinogenesis and platelet activation and inhibition. Previous studies have demonstrated that mercury decreases the production of nitric oxide (NO) and alters the expression of $\mathrm{NO}$ synthase (NOS) (27). $\mathrm{HgCl}_{2}$ at concentrations of 0.5 to $10 \mu \mathrm{M}$ produces vasoconstriction, reduces the endothelial vasodilator response and stimulates a cyclooxygenase (COX)-derived vasoconstrictor (28). In addition, several studies have shown that mercury induces oxidative stress with subsequent oxidative damage to several organs or systems (23). Glutathione (GSH) depletion by mercury may be a trigger for the production of reactive oxygen species (ROS) that induce lipid, protein and DNA oxidation (23). Vascular endothelium is highly sensitive to oxidative stress and this is the main cause of endothelial dysfunction observed in cardiovascular diseases such as hypertension and atherosclerosis $(22,29)$. Most mercury toxicity studies are performed with high (micromolar) concentrations of mercury and under acute exposure. Then, given the idea that relatively high blood levels are more frequently used to indicate mercury as an environmental risk factor for cardiovascular diseases, we recently developed a methodology involving controlled chronic mercury administration that attains a concentration of $8 \mathrm{ng} / \mathrm{mL}(\sim 29 \mathrm{nM})$ in blood (25) to better understand the endothelial modulation of vascular responses.

\section{Lead}

Lead is abundant in the earth's crust, with average concentrations between 10 and $20 \mathrm{mg} / \mathrm{kg}$ in the soil. The greatest natural sources are volcanic activity and geochemical weathering. It is estimated that the natural emissions of lead are about 19,000 tons. However, anthropogenic processes such as painting, addition of lead to petrol, battery manufacturing, etc., are important processes responsible for the environmental presence of lead (30). Once lead particles go into the air they are removed by deposition, transferred to the surface and rapidly distributed in water or sediments according to the $\mathrm{pH}$ of dissolved salts (30). Therefore, lead has become one of the most common environmental contaminants resulting from external sources. 
This metal is recognized as a common environmental and occupational health hazard (31) because of numerous industrial activities that favor its wide distribution. Human beings usually have lead in their organism (8) which, upon sufficient exposure and/or accumulation in the body $(32,33)$, can exert adverse effects. Although having no physiological function, its toxic effects on humans and animals have long been known, affecting almost all organs and systems in the human body.

The effects of lead on human health depend on plasma levels and on the duration of exposure. Blood lead levels up to $29 \mu \mathrm{g} / \mathrm{dL}$ ( 1 to $1.4 \mu \mathrm{M}$ ) led to a $46 \%$ increase in allcause mortality, a $39 \%$ increase in circulatory mortality and a $68 \%$ increase in cancer mortality (34). In addition, chronic exposure to low levels of lead causes hypertension in animals and humans (33,34). Vupputuri et al. (35), when re-evaluating the results of the Third National Health and Nutrition Examination Survey (36), reported a positive correlation between plasma lead concentration and arterial pressure in black men and women.

The limit of blood lead concentration recommended by the Agency for Toxic Substances and Disease Registry (31) is $60 \mu \mathrm{g} / \mathrm{dL}$ in occupationally exposed adults. However, an increase in arterial pressure has been reported for individuals with blood lead concentrations of 31.4 and $53.5 \mu \mathrm{g} / \mathrm{dL}$ (35-37). Previous studies on lead toxicity have reported $42.5 \pm 2.3$ and $58.7 \mu \mathrm{g} / \mathrm{dL}(38,39)$, blood concentrations that are similar to those found in the occupationally exposed population. In Brazil (Ministério do Trabalho; Norma Regulamentadora No. 7), the reference values for blood lead concentrations have been established at 40 $\mu \mathrm{g} / \mathrm{dL}$ for unexposed persons and at $60 \mu \mathrm{g} / \mathrm{dL}$ for exposed persons.

A close relationship between lead exposure and hypertension has been reported in experimental studies on animals and in epidemiological reports (8). Lead-induced hypertension is reported to result from the inhibition of NKA (39) and from the reduced bioavailability of NO plus an increased endothelial release of endothelin $(40,41)$. Free radicals reducing $\mathrm{NO}$ bioavailability (42) and depletion of antioxidant reserves $(8,43)$ or their up-regulation $(39)$ have also been reported. Peripheral or central nervous mechanisms, such as the increase of sympathetic nerve activity, the reduction of baroreflex sensitivity and the reduction of parasympathetic tone (33), are also involved in lead-induced hypertension. In addition, Carmignani et al. $(32,41)$ reported increased myocardial inotropism and increased ACE activity in rats exposed to $60 \mathrm{ppm}$ lead acetate for 10 months.

Previous studies have shown that possible mechanisms involved in lead-induced hypertension are due to alterations in vascular tone $(8,39)$. Changes in vascular reactivity have not been extensively described in the presence of low lead concentrations and in the initial stages of lead exposure. However, studies have shown that chronic exposure to low lead concentrations induces aorta vasoconstriction (44).
On the other hand, chronic exposure to lead (100 ppm for 10 months) decreased the contractile response induced by 5 -hydroxytryptamine (5-HT) in the aorta of lead-treated rats (45). These effects could be mediated by increased production of ROS and vasoconstrictor prostanoids of the cyclooxygenase pathway $(26,39)$.

\section{Gadolinium}

Gadolinium is a trivalent lanthanide cation currently used as a magnetic resonance contrast medium, the gadobenate dimeglumine (Gd-bopta) (3), which blocks calcium channel stretch at high concentrations $(10 \mu \mathrm{M})(46)$. However, concerns about contrast-induced nephropathy have been reported (47).

In addition to acting as a calcium channel blocker, gadolinium, at low concentration, can interact with the signaling involved in intracellular and extracellular ATP hydrolysis (48). Escalada et al. (49) reported that $3 \mu \mathrm{M}$ gadolinium, a concentration that does not block calcium channels, has a potent inhibitory action on ecto-nucleoside triphosphate diphosphohydrolase (E-NTPDase) activity from the electric organ of Torpedo marmorata. Extracellular nucleotides are important molecules involved in the regulation of different biological processes including vascular tone. When released as a neurotransmitter from the sympathetic terminals, ATP binds to P2X receptors of vascular smooth muscle cells, producing vasoconstriction. When binding to endothelial P2Y receptors, ATP leads to vasodilatation $(48,50)$. ATP exerts other effects on the vascular beds, such as control of smooth muscle and endothelial cell proliferation $(48,50)$. The action of extracellular nucleotides is terminated by the ENTPDase family. NTPDase1 is the major ectonucleotidase expressed in the vasculature $(48,50)$ and its action limits platelet activation by ATP hydrolysis $(48,50)$. NTPDase 2 is another ectonucleotidase associated with the vasculature that preferentially converts ATP to ADP (50). Following the action of E-NTPDases, ecto-5'-nucleotidase is responsible for the end of nucleotide signaling by converting AMP to adenosine (51).

Gadolinium also affects ACE activity as a chelate by a transmetallation effect with zinc (52). This enzyme is a metallopeptidase containing zinc and therefore the possibility of a transmetallation effect is likely. Angiotensin II resulting from the action of ACE is the major effector of the renin-angiotensin system (RAS) (53). It activates the $A T_{1}$ receptor, has vasoconstriction and pressor effects and also causes thrombosis, inflammation and vascular and myocardial hypertrophy (53).

Interestingly, despite these actions, gadolinium has not been defined as a toxic agent. There is no toxicological information and recommended exposure limits have not been defined.

After describing the main characteristics of mercury, lead and gadolinium and considering that mercury and lead 
are known to produce hypertension and gadolinium affects the RAS, we will focus on actions of these three metals on vascular reactivity. Their effects will be briefly described in protocols that are commonly employed in several laboratories mainly using vascular rings.

\section{Effects of heavy metals on vascular reactivity}

\section{Changes in vascular responses to phenylephrine}

We used the following protocol to test the general characteristics of vascular reactivity. Rats are anesthetized with sodium thiopental ( $50 \mathrm{mg} / \mathrm{kg}$, ip) and killed by exsanguination. Thoracic aortas are removed and placed in cold oxygenated Krebs-Hanseleit bicarbonate buffer (KHB), carefully dissected out and cleaned of fat and connective tissue. For reactivity experiments, the aortas are divided into cylindrical segments $4 \mathrm{~mm}$ in length and cut into rings 4-6 $\mathrm{mm}$ in length. Rings are then mounted between parallel wires in tissue baths at $37^{\circ} \mathrm{C}$ containing $\mathrm{KHB}$ gassed with $95 \% \mathrm{O}_{2}$ and $5 \% \mathrm{CO}_{2}$ to maintain the $\mathrm{pH}$ at 7.4. However, for lead (as lead acetate) the bicarbonate buffer cannot be used because it precipitates. $\mathrm{pH}$ can be adjusted with $20 \mathrm{mM}$ HEPES plus $4 \mathrm{mM} \mathrm{NaOH}$. Rings are stretched to an optimal resting tension of $1 \mathrm{~g}$ and isometric tension is recorded using an isometric force displacement transducer. After 45-min equilibration each aortic ring is exposed twice to $75 \mathrm{mM} \mathrm{KCl}$ to obtain its maximum contractility. Rings are then sequentially washed and re-equilibrated and allowed to relax to baseline. Thirty minutes later, the rings are contracted with $1 \mu \mathrm{M}$ phenylephrine and $10 \mu \mathrm{M}$ acetylcholine $(\mathrm{ACh})$ is then added to assess the integrity of the endothelium. A relaxation equal to or greater than $90 \%$ indicates functional integrity of the endothelium. Smooth muscle viability is tested using sodium nitroprusside (SNP, 0.1 $\mathrm{mg} / \mathrm{mL}$ ) in rings previously contracted with phenylephrine. After $30 \mathrm{~min}$, cumulative concentration-response curves for phenylephrine $(0.1 \mathrm{nM}-300 \mu \mathrm{M})$ are generated.

The incubation of segments with mercury $\left(\mathrm{HgCl}_{2}\right)$ for 60 min promotes an increase in the reactivity to phenylephrine both at high $(0.5$ to $10 \mu \mathrm{M})$ and low $(6 \mathrm{nM})$ concentrations $(54,55)$. This increased reactivity appears as an increased Rmax and sensitivity. Gadolinium ( $3 \mu \mathrm{M}$ as $\mathrm{GdCl}_{3}$ ) promotes similar responses (56) but lead increases vascular reactivity when administered only at high concentration $(100 \mu \mathrm{M})$. At lower lead concentration ( $5 \mathrm{nM})$, reactivity to phenylephrine decreases.

When controlled chronic mercury treatments are performed using exposure to low doses for 30 days, with a blood concentration of $8 \mathrm{ng} / \mathrm{mL}(\sim 29 \mathrm{nM})$ being reached, vascular reactivity to phenylephrine increases in $\mathrm{Hg}$-treated rats $(25,26)$. Mercury treatment also increases 5 -HT-induced vasoconstriction in coronary arteries (27). A similar increase of vascular reactivity was obtained with lead treatments for 30 days or more (57). However, exposure of rats to low lead concentrations for 7 days decreased the contractile response of aortic rings to phenylephrine (58). These findings confirm previous reports clearly suggesting that the effects of lead are concentration and time dependent (32). Regarding gadolinium, there are no reports about chronic treatments with low concentrations.

\section{Role of the endothelium in the effects of mercury, lead and gadolinium}

To evaluate its role in the vascular effects of heavy metals, the endothelium is removed by gently rubbing the intimal surface with a stainless steel rod. The effectiveness of endothelial removal is confirmed by the absence of the relaxation induced by $10 \mu \mathrm{M}$ Ach in aortic segments precontracted with $1 \mu \mathrm{M}$ phenylephrine. Removal is considered to be adequate when Ach-induced relaxation is less than $10 \%$ or a contraction is observed.

Removal of the endothelium increases vasoconstrictor responses or rat aortic segments to phenylephrine. This indicates that the vascular response to phenylephrine is negatively modulated by the endothelium. The effects on the phenylephrine response of all three metals, acutely administered, were dependent on the integrity of this vascular layer. Thus, when the endothelium is removed their actions are abolished $(25,56,57)$. This endothelial dependence is observed for low and high concentrations of mercury and lead. The only effect reported thus far for gadolinium was obtained with a concentration of $3 \mu \mathrm{M}(56)$.

The effects on the phenylephrine response observed with chronic administration of low concentrations of mercury and lead also show endothelial dependence because endothelial removal abolishes the effects of both metals. The effects of mercury and gadolinium, which increase vascular reactivity to phenylephrine, are abolished by endothelium removal and the reduced vascular reactivity to phenylephrine observed for lead is also abolished.

\section{Effects of mercury, lead and gadolinium on endothelial modulation of vascular responses to NO}

The NOS inhibitor NG-nitro-L-arginine methyl ester (LNAME, $100 \mu \mathrm{M}$ ) is commonly used to test the endothelial modulation of vascular responses to NO. L-NAME has a potentiating effect on the vasoconstrictor response to phenylephrine, which indicates the negative endothelial NO modulation of such response. The results also give information about NO bioavailability. This is important to consider because we can have an enhanced NO production which, however, can be destroyed, reducing bioavailability. To better explain this issue some protocols can be performed such as analysis of production blockade, NO production stimulated with Ach, definition of which NOS (eNOS, nNOS, and iNOS) are involved, and which factors are destroying NO.

Acute administration of $6 \mathrm{nM} \mathrm{HgCl}_{2}$ reduces the negative endothelial modulation of phenylephrine responses 
(54). However, the endothelial modulation is increased after acute lead treatment, suggesting that the endothelium tries to adapt to the new environmental conditions and that the increased reactivity depends on factors other than NO production. Regarding the effects of gadolinium, L-NAME treatment in the presence of gadolinium does not change the reactivity to phenylephrine. This finding suggests that the increased vascular reactivity increment does not depend on $\mathrm{NO}$ but depends on another endothelial-derived factor.

Chronic treatments have been reported for mercury and lead but not for gadolinium. Mercury reduces the effect of $L-$ NAME effect, as seen with endothelial denudation. However, lead treatment for 7 days enhanced endothelial modulation by NO, which would explain the reduced phenylephrine responses observed after lead treatment. Our findings suggest that this increased NO production is dependent on an increased activity of eNOS and iNOS.

\section{Effects of mercury, lead and gadolinium on the endothelial modulation of vascular responses by prostanoids}

Prostaglandins are endothelial factors that participate in vascular responses. The involvement of prostanoids in phenylephrine responses was investigated using $10 \mu \mathrm{M}$ indomethacin, a well-known non-selective COX inhibitor.

Indomethacin reverses the increased reactivity to phenylephrine induced by acute administration of $6 \mathrm{nM}$ $\mathrm{HgCl}_{2}$ (54). Chronic treatment also induces the same response caused by an increased production of contractile prostanoids (prostaglandin 2 and thromboxane A2) derived from COX-2.

Similar effects are also promoted by a high concentration of lead acetate $(100 \mu \mathrm{M})$. However, under low lead concentrations indomethacin does not alter the pressor effects of phenylephrine, suggesting that prostanoids do not play a role in the actions of lead (58). The effects of gadolinium on COX activity have not been described.

\section{Effects of mercury, lead and gadolinium on endothelial modulation of vascular responses to endothelial-derived hyperpolarizing factors}

Endothelial-derived hyperpolarizing factors (EDHFs) are important vasodilator agents that act by increasing the permeability of $\mathrm{K}^{+}$channels. Tetraethylammonium (TEA, 1 to $5 \mathrm{mM}$ ) is commonly used to test the dependence on hyperpolarizing factors. TEA blocks several potassium channels and is used as a first attempt to define the role of these channels in an intervention with toxic metals, for example. Instead of a single one, several compounds are considered to be EDHFs. NO, epoxyeicosatrienoic acids, anandamide, and even $\mathrm{H}_{2} \mathrm{O}_{2}$ have been described as EDHFs depending on the vascular bed studied.

Mercury and lead indirectly affect EDHF production because both can reduce $\mathrm{NO}$ bioavailability, inducing free radical generation $(8,25,26)$. A short-term exposure to low lead concentrations, however, reduces vascular reactivity and seems to stimulate $\mathrm{K}^{+}$channels in vascular smooth muscle cells (58). Again, the effects of gadolinium on EDHF activity have not been described.

\section{Role of free radicals in the effects of mercury, lead and gadolinium on vascular responses}

Several compounds can be used to investigate the possibility that free radicals play a role in the effects of mercury, lead or gadolinium on the pressure response to phenylephrine: tempol, an agent that mimics superoxide dismutase (4-hydroxy-tempo, $1 \mu \mathrm{M}$ ); deferoxamine, a free radicals scavenger $(300 \mu \mathrm{M})$; the superoxide anion scavenger superoxide dismutase (SOD, $150 \mathrm{U} / \mathrm{mL}$ ); catalase (1000 U/ $\mathrm{mL}$ ), a scavenger of $\mathrm{H}_{2} \mathrm{O}_{2}$, and the $\mathrm{NAD}(\mathrm{P}) \mathrm{H}$ oxidase inhibitor apocynin $(0.3 \mathrm{mM})$. The oxidative fluorescent dye dihydroethidium (DHE) is used to evaluate $\mathrm{O}_{2}{ }^{-}$production in situ (59). Inside the cells, hydroethidine is oxidized to ethidium bromide in the presence of $\mathrm{O}_{2}$ - because it freely permeates cells and is then trapped by intercalation with DNA.

Mercury at low and high concentrations stimulates free radical generation after both acute and chronic treatment. This increased free radical generation is usually responsible for the reduction of NO bioavailability. Thus, we have observed that: 1) vascular $\mathrm{O}_{2}$.- $^{-}$production and plasma oxidative stress are greater in rats treated with mercury chloride, 2) mercury treatment also increases vascular mRNA levels of the $\mathrm{NAD}(\mathrm{P}) \mathrm{H}$ oxidase subunits NOX-1 and NOX-4 (27), and 3) several antioxidants abolish the increased vasoconstrictor responses observed in vessels from mercury-treated rats $(25,27)$.

Lead is also described as an inducer of free radical production (8). The metal increases superoxide production and the blockade of its effects by SOD, catalase and apocynin shows a reduction of reactivity in the dose-response curve to phenylephrine. These findings also suggest that NADPH oxidase is also a putative site for the effect of lead in increasing free radical generation.

\section{Effects of mercury, lead and gadolinium on ACE activity}

The RAS plays an important role in the regulation of the cardiovascular system. The RAS was initially described as systemic RAS but a local RAS has been recently described in several tissues. The classic RAS depends on the action of renin. This enzyme changes angiotensinogen to angiotensin I that is converted to angiotensin II by ACE. ACE is an enzyme that has two zinc atoms in its molecule, which can be changed by other metals by a transmetallation process.

The participation of the RAS in the concentrationresponse curve to phenylephrine was studied in control or treated preparations by the blockade of ACE or the AT 1 angiotensin II receptor with $1 \mu \mathrm{M}$ enalaprilate and $10 \mu \mathrm{M}$ losartan, respectively. When the $\mathrm{AT}_{1}$ receptor is blocked, 
angiotensin II is present and its effects on $\mathrm{AT}_{2}$ receptors might take place because they are operational. When ACE is blocked by enalaprilate, no angiotensin II is produced. Then, if the action of the metals is blocked, it suggests that ACE is being stimulated by the metals. The effects of all three metals are blocked when both drugs are used.

A curious finding is that when low concentrations of these metals are used ACE is stimulated. However, when high concentrations of mercury and gadolinium are used ACE is blocked (52). These effects have one interesting explanation, i.e., the transmetallation phenomenon (52). ACE has zinc attached to both active sites, which can be changed by other metals. The fact that at higher concentrations ACE is inhibited is also explained by another phenomenon called hormesis (60). Hormesis explains why toxic agents and venoms can activate or reduce their effects and as concentrations change the effects turn in the opposite direction.

As a final remark, the findings presented here suggest

\section{References}

1. Clarkson TW, Magos L, Myers GJ. The toxicology of mercury - current exposures and clinical manifestations. N Engl J Med 2003; 349: 1731-1737.

2. $\mathrm{WHO}$ - World Health Organization. Guidelines on regulatory expectations related to the elimination, reduction or replacement of thimerosal in vaccines. Technical Report Series 2004; 926: 95-102.

3. Klein C, Gebker R, Kokocinski T, Dreysse S, Schnackenburg $\mathrm{B}$, Fleck E, et al. Combined magnetic resonance coronary artery imaging, myocardial perfusion and late gadolinium enhancement in patients with suspected coronary artery disease. J Cardiovasc Magn Reson 2008; 10: 45.

4. Clarkson TW. The pharmacology of mercury compounds. Annu Rev Pharmacol 1972; 12: 375-406.

5. Anner BM, Moosmayer M, Imesch E. Mercury blocks Na-KATPase by a ligand-dependent and reversible mechanism. Am J Physiol 1992; 262: F830-F836.

6. Oliveira EM, Vassallo DV, Sarkis JJ, Mill JG. Mercury effects on the contractile activity of isolated heart muscle. Toxicol Appl Pharmacol 1994; 128: 86-91.

7. Hechtenberg S, Beyersmann D. Inhibition of sarcoplasmic reticulum $\mathrm{Ca}^{(2+)}$-ATPase activity by cadmium, lead and mercury. Enzyme 1991; 45: 109-115.

8. Patrick L. Lead toxicity part II: the role of free radical damage and the use of antioxidants in the pathology and treatment of lead toxicity. Altern Med Rev 2006; 11: 114-127.

9. Bakir F, Damluji SF, Amin-Zaki L, Murtadha M, Khalidi A, al-Rawi NY, et al. Methylmercury poisoning in Iraq. Science 1973; 181: 230-241.

10. Klaassen $C D$. Heavy metals and the heavy metals antagonists. In: Gilman AG, Rall TW, Nies AS, Taylor P (Editors), Goodman and Gilman's the pharmacological basis of therapeutics. 8th edn. New York: Pergamon Press; 1990. p 1592-1614.

11. Abramson JJ, Salama G. Critical sulfhydryls regulate calcium release from sarcoplasmic reticulum. J Bioenerg that mercury, lead and gadolinium, even at low doses or concentrations, affect vascular reactivity. Their actions are mediated by the endothelium and result mainly from an enhanced production of free radicals and an increased production of angiotensin II by stimulation of the local ACE. The findings reported here provide further evidence that toxic metals, even at low doses, could be an environmental risk factor for cardiovascular disease.

These results also suggest that continuous exposure to these metals followed by their absorption may be hazardous to cardiovascular function and the current reference values, considered to be without risk, need to be reduced.

\section{Acknowledgments}

Research supported by CAPES and CNPq/FAPES/ FUNCITEC (\#39767531/07), Brazil, and MCINN (\#SAF 2009-07201) and ISCIII (Red RECAVA, \#RD06/0014/0011), Spain.

Biomembr 1989; 21: 283-294.

12. Chiamvimonvat N, O'Rourke B, Kamp TJ, Kallen RG, Hofmann F, Flockerzi V, et al. Functional consequences of sulfhydryl modification in the pore-forming subunits of cardiovascular $\mathrm{Ca}^{2+}$ and $\mathrm{Na}^{+}$channels. Circ Res 1995; 76: 325-334.

13. Stern $\mathrm{AH}$. Balancing the risks and benefits of fish consumption. Ann Intern Med 2005; 142: 949.

14. McKelvey W, Gwynn RC, Jeffery N, Kass D, Thorpe LE, Garg RK, et al. A biomonitoring study of lead, cadmium, and mercury in the blood of New York city adults. Environ Health Perspect 2007; 115: 1435-1441.

15. Chen C, Qu L, Li B, Xing L, Jia G, Wang T, et al. Increased oxidative DNA damage, as assessed by urinary 8-hydroxy2'-deoxyguanosine concentrations, and serum redox status in persons exposed to mercury. Clin Chem 2005; 51: 759767.

16. WHO (World Health Organization). Environmental health criteria 101: Methylmercury. Geneva: World Health Organization; 1990.

17. Nriagu JO, Pfeiffer WC, Malm O, Magalhaes de Souza CM, Mierle G. Mercury pollution in Brazil. Nature 1992; 356: 389.

18. Halbach $\mathrm{S}$. Combined estimation of mercury species released from amalgam. J Dent Res 1995; 74: 1103-1109.

19. Bjorkman L, Sandborgh-Englund G, Ekstrand J. Mercury in saliva and feces after removal of amalgam fillings. Toxicol Appl Pharmacol 1997; 144: 156-162.

20. Langworth S, Sallsten G, Barregard L, Cynkier I, Lind ML, Soderman E. Exposure to mercury vapor and impact on health in the dental profession in Sweden. J Dent Res 1997; 76: $1397-1404$.

21. Wakita Y. Hypertension induced by methyl mercury in rats. Toxicol Appl Pharmacol 1987; 89: 144-147.

22. Salonen JT, Seppanen K, Lakka TA, Salonen R, Kaplan GA. Mercury accumulation and accelerated progression of ca- 
rotid atherosclerosis: a population-based prospective 4-year follow-up study in men in eastern Finland. Atherosclerosis 2000; 148: 265-273.

23. Houston MC. The role of mercury and cadmium heavy metals in vascular disease, hypertension, coronary heart disease, and myocardial infarction. Altern Ther Health Med 2007; 13: S128-S133.

24. Vassallo DV, Moreira CM, Oliveira EM, Bertollo DM, Veloso TC. Effects of mercury on the isolated heart muscle are prevented by DTT and cysteine. Toxicol Appl Pharmacol 1999; 156: 113-118.

25. Wiggers GA, Pecanha FM, Briones AM, Perez-Giron JV, Miguel M, Vassallo DV, et al. Low mercury concentrations cause oxidative stress and endothelial dysfunction in conductance and resistance arteries. Am J Physiol Heart Circ Physiol 2008; 295: H1033-H1043.

26. Pecanha FM, Wiggers GA, Briones AM, Perez-Giron JV, Miguel M, Garcia-Redondo AB, et al. The role of cyclooxygenase (COX)-2 derived prostanoids on vasoconstrictor responses to phenylephrine is increased by exposure to low mercury concentration. J Physiol Pharmacol 2010; 61: 29-36.

27. Furieri LB, Galan M, Avendano MS, Garcia-Redondo AB, Aguado A, Martinez S, et al. Endothelial dysfunction of rat coronary arteries after exposure to low concentrations of mercury is dependent on reactive oxygen species. $\mathrm{Br} J$ Pharmacol 2011; 162: 1819-1831.

28. da Cunha V, Rossoni LV, Oliveira PA, Poton S, Pretti SC, Vassallo DV, et al. Cyclooxygenase inhibition reduces blood pressure elevation and vascular reactivity dysfunction caused by inhibition of nitric oxide synthase in rats. Clin Exp Hypertens 2000; 22: 203-215.

29. Touyz RM. Reactive oxygen species, vascular oxidative stress, and redox signaling in hypertension: what is the clinical significance? Hypertension 2004; 44: 248-252.

30. WHO (World Health Organization). IPCS (International Program in Chemical Safety). Environmental health criteria85-Lead environmental aspects. Geneva: World Health Organization; 1989.

31. ATSDR (Agency for Toxic Substances and Disease Registry). Toxicological profile for lead (draft for public comment). Annual report. Atlanta: Department of Health and Human Services, Public Health Service; 2005.

32. Carmignani M, Boscolo P, Poma A, Volpe AR. Kininergic system and arterial hypertension following chronic exposure to inorganic lead. Immunopharmacology 1999; 44: 105-110.

33. Navas-Acien A, Guallar E, Silbergeld EK, Rothenberg SJ. Lead exposure and cardiovascular disease - a systematic review. Environ Health Perspect 2007; 115: 472-482.

34. Lustberg M, Silbergeld E. Blood lead levels and mortality. Arch Intern Med 2002; 162: 2443-2449.

35. Vupputuri S, He J, Muntner P, Bazzano LA, Whelton PK, Batuman V. Blood lead level is associated with elevated blood pressure in blacks. Hypertension 2003; 41: 463-468.

36. Den Hond E, Nawrot T, Staessen JA. The relationship between blood pressure and blood lead in NHANES III. National Health and Nutritional Examination Survey. J Hum Hypertens 2002; 16: 563-568.

37. Ehrlich R, Robins T, Jordaan E, Miller S, Mbuli S, Selby P, et al. Lead absorption and renal dysfunction in a South African battery factory. Occup Environ Med 1998; 55: 453-460.

38. Grizzo LT, Cordellini S. Perinatal lead exposure affects nitric oxide and cyclooxygenase pathways in aorta of weaned rats. Toxicol Sci 2008; 103: 207-214.

39. Farmand F, Ehdaie A, Roberts CK, Sindhu RK. Leadinduced dysregulation of superoxide dismutases, catalase, glutathione peroxidase, and guanylate cyclase. Environ Res 2005; 98: 33-39.

40. Khalil-Manesh F, Gonick HC, Weiler EW, Prins B, Weber MA, Purdy RE. Lead-induced hypertension: possible role of endothelial factors. Am J Hypertens 1993; 6: 723-729.

41. Carmignani M, Volpe AR, Boscolo P, Qiao N, Di Gioacchino $M$, Grilli A, et al. Catecholamine and nitric oxide systems as targets of chronic lead exposure in inducing selective functional impairment. Life Sci 2000; 68: 401-415.

42. Vaziri ND, Ding Y, Ni Z. Compensatory up-regulation of nitric-oxide synthase isoforms in lead-induced hypertension; reversal by a superoxide dismutase-mimetic drug. $J$ Pharmacol Exp Ther 2001; 298: 679-685.

43. Kasperczyk S, Kasperczyk A, Ostalowska A, Dziwisz M, Birkner E. Activity of glutathione peroxidase, glutathione reductase, and lipid peroxidation in erythrocytes in workers exposed to lead. Biol Trace Elem Res 2004; 102: 61-72.

44. Heydari A, Norouzzadeh A, Khoshbaten A, Asgari A, Ghasemi A, Najafi S, et al. Effects of short-term and subchronic lead poisoning on nitric oxide metabolites and vascular responsiveness in rat. Toxicol Lett 2006; 166: 88-94.

45. Zhang LF, Peng SQ, Wang S. Decreased aortic contractile reaction to 5-hydroxytryptamine in rats with long-term hypertension induced by lead $\left(\mathrm{Pb}^{(2+)}\right)$ exposure. Toxicol Lett 2009; 186: 78-83.

46. Caldwell RA, Clemo HF, Baumgarten CM. Using gadolinium to identify stretch-activated channels: technical considerations. Am J Physiol 1998; 275: C619-C621.

47. Perazella MA. Gadolinium-contrast toxicity in patients with kidney disease: nephrotoxicity and nephrogenic systemic fibrosis. Curr Drug Saf 2008; 3: 67-75.

48. Burnstock G. Pathophysiology and therapeutic potential of purinergic signaling. Pharmacol Rev 2006; 58: 58-86.

49. Escalada A, Navarro P, Ros E, Aleu J, Solsona C, MartinSatue M. Gadolinium inhibition of ecto-nucleoside triphosphate diphosphohydrolase activity in Torpedo electric organ. Neurochem Res 2004; 29: 1711-1714.

50. Sevigny J, Sundberg C, Braun N, Guckelberger O, Csizmadia E, Qawi I, et al. Differential catalytic properties and vascular topography of murine nucleoside triphosphate diphosphohydrolase 1 (NTPDase1) and NTPDase2 have implications for thromboregulation. Blood 2002; 99: 28012809.

51. Frassetto SS, Schetinger MR, Schierholt R, Webber A, Bonan CD, Wyse AT, et al. Brain ischemia alters platelet ATP diphosphohydrolase and 5'-nucleotidase activities in naive and preconditioned rats. Braz J Med Biol Res 2000; 33: 1369-1377.

52. Corot C, Idee JM, Hentsch AM, Santus R, Mallet C, Goulas $\mathrm{V}$, et al. Structure-activity relationship of macrocyclic and linear gadolinium chelates: investigation of transmetallation effect on the zinc-dependent metallopeptidase angiotensinconverting enzyme. J Magn Reson Imaging 1998; 8: 695702.

53. Touyz RM, Berry C. Recent advances in angiotensin II signaling. Braz J Med Biol Res 2002; 35: 1001-1015.

54. Wiggers GA, Stefanon I, Padilha AS, Pecanha FM, Vassallo DV, Oliveira EM. Low nanomolar concentration of mercury 
chloride increases vascular reactivity to phenylephrine and local angiotensin production in rats. Comp Biochem Physiol C Toxicol Pharmacol 2008; 147: 252-260.

55. da Cunha V, Souza HP, Rossoni LV, Franca AS, Vassallo DV. Effects of mercury on the isolated perfused rat tail vascular bed are endothelium-dependent. Arch Environ Contam Toxicol 2000; 39: 124-130.

56. Angeli JK, Ramos DB, Casali EA, Souza DO, Sarkis JJ, Stefanon I, et al. Gadolinium increases the vascular reactivity of rat aortic rings. Braz J Med Biol Res 2011; 44: 445-452.

57. Silveira EA, Lizardo JH, Souza LP, Stefanon I, Vassallo DV. Acute lead-induced vasoconstriction in the vascular beds of isolated perfused rat tails is endothelium-dependent. Braz $J$
Med Biol Res 2010; 43: 492-499.

58. Fiorim J, Ribeiro Junior RF, Silveira EA, Padilha AS, Vescovi $\mathrm{MV}$, de Jesus $\mathrm{HC}$, et al. Low-level lead exposure increases systolic arterial pressure and endothelium-derived vasodilator factors in rat aortas. PLoS One 2011; 6: e17117.

59. Jimenez-Altayo F, Briones AM, Giraldo J, Planas AM, Salaices $M$, Vila E. Increased superoxide anion production by interleukin1 beta impairs nitric oxide-mediated relaxation in resistance arteries. J Pharmacol Exp Ther 2006; 316: 42-52.

60. Calabrese EJ, Baldwin LA. Hormesis as a biological hypothesis. Environ Health Perspect 1998; 106 (Suppl 1): 357-362. 